\title{
Effect of Oil Temperature on Load Capacity and Friction Power Loss in Point Contact Elasto-hydrodynamic Lubrication
}

\author{
Hassan Sami ${ }^{1 *}$, Zaid S. Hammoudi ${ }^{2}$, Lutfy Y. Zidane ${ }^{2}$
}

\section{Authors affiliations: \\ $\left.1^{*}\right)$ Mechanical Eng. Dep. \\ University of Diyala \\ eng.has8san@gmail.com \\ 2) Mechanical Eng. Dep. \\ University of Diyala}

\section{Paper History:}

Received: $8^{\text {th }}$ April 2019

Revised: $8^{\text {th }}$ May 2019

Accepted: $17^{\text {th }}$ Sep. 2019

\begin{abstract}
This study presents a numerical analysis for point contact Elastohydrodynamic lubrication EHL. The oils used are (0W-30 and 10W-40) as lubricants. The pressure and film-thickness profiles for point contact EHL are evaluated. The aims of this study are to estimate the effect of oil's temperature on friction force, coefficient of friction and load carrying capacity. By using FORTRAN program, the Forward-iterative method is used, to solve two dimensional (2D) EHL problem. The viscosity is updating in the solution by using Roeland's model. After the convergence of pressure is done, the friction force, friction power losses, and friction coefficient are calculated. The temperature used ranges from $\left(-20\right.$ to $\left.120{ }^{\circ} \mathrm{C}\right)$. The results showed the film-thickness decreases with the increasing of temperature. Though the maximum pressure is not affected, only the pressure distribution and profile are changed, inlet pressure decreases and the pressure profile tends towards a hertzian (dry contact) one. The friction force and the coefficient of friction decrease with the increasing of temperature.
\end{abstract}

Keywords: Elasto-Hydrodynamic Lubrication; Point Contact; Numerical Analysis; Friction Force.

$$
\begin{aligned}
& \text { تأثير درجة حرارة الزيت على الملل المسلط وطاقة الهحتك الضائعة في التزييت } \\
& \text { الهيدروديناميكي المرن لحالة التلامس الدائري } \\
& \text { حسن سامي، زيد سالم حمودي، لطفي يوسف زيدان } \\
& \text { الملاصة: } \\
& \text { تقدم هذه الدراسة تحليلاً عددياً للتزييت الهيدروديناميكي المرن لحالة التماس الدائري باستخدام نوعين من }
\end{aligned}
$$

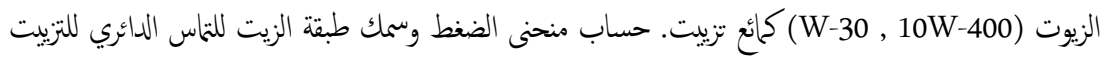

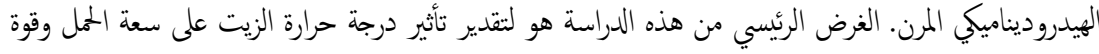

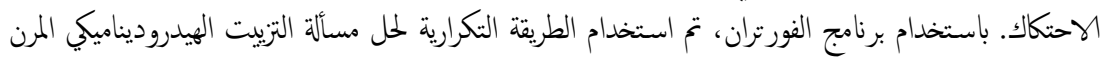

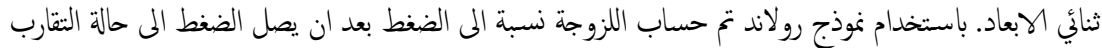

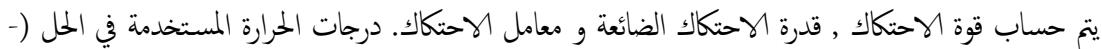

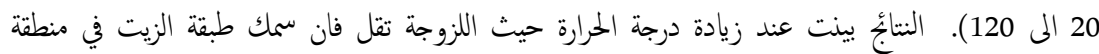

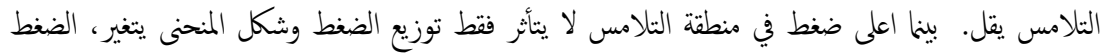

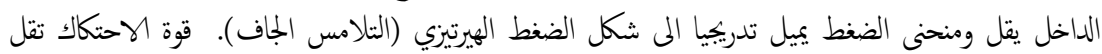

$$
\begin{aligned}
& \text { بزيادة درجة الحرارة. }
\end{aligned}
$$

\section{Introduction}

Elasto-hydrodynamic Lubrication (EHL or EHD) is the type of hydrodynamic lubrication (HD), which includes physical interaction between the elements in contact, which is caused by the fluid of lubricants. The surfaces of contact are elastically deformed, and as the viscosity changes with pressure which plays essential roles [1]. The surfaces of contacts in various engineering applications, such as rolling contact bearings, cams, gears, etc., are not conformal. However, the resulting regions of contacts are very small, and the resulting pressure are high [2]. Generally, EHL is divided into two types of problems based on their contacted bodies, line contact 1D, and point contact 2D. The line contact problems are presented as a cylindrical Roller bearing. The rolling and load regions are angularly positioned in line contact type, and the rolling region is smaller than the

NJES is an open access Journal with ISSN 2521-9154 and eISSN 2521-9162

This work is licensed under a Creative Commons Attribution-NonCommercial 4.0 International License 
load region. The point contact problems is represented as a contact between a spherical balls, or a contact between spherical ball with plane, as shown in figure (1) [3].

It is significant to appreciate the major EHL features, and to be able to predict the key properties of EHL problems, such as film-thickness, pressure and friction. EHL friction is becoming gradually important in the studies for increasing the mechanical transmission efficiency, and thus minimizing energy consumptions [4]. This study will summarize some of the major EHL features. Especially how to determine EHL minimum film-thickness, friction force and friction coefficient for changes in temperature. Many researches focus on friction in elastohydrodynamic lubrication [5]; found in, among others bearings, and gears. Wang WZ, et al [6] presents a numerical method to simulate sliding friction between engineering surfaces, with (3D) roughness in point contacts. By using "Universal Material Tester" (UMT), the friction is measured with a different sliding speed in rotary motion and fixed load. Roland $\mathrm{L}$, et al $[7,8]$ made a friction test by using a ball-ondisc test rig. In addition, they calculated the friction coefficient with velocity and slide to roll ratio SRR. Several tests are made with a number of parameters that changed while studying the coefficient of friction, such as surface roughness, oil viscosity, oil temperature, and SRR. The results of this study show that the mapping is efficient in showing the different types of friction that may occur in an EHL contact. Moreover, they show that the friction behavior can be strongly affected by varying surface roughness, base oil viscosity, and operating temperature.

Numerical calculation that are based on point contact calculation of pressure and film-thickness by Hamrock B.J. and Dowson D. [9] will be used. Hamrock and D. Dowson illustrated how to solve EHD Problems of highly loaded point of contact by evaluating the elastic-deformation and film-thickness. Especially at the inlet area, and close to the pressure spike, where $\mathrm{dP} / \mathrm{dX}$ is high. This technique is used in this paper, because it gives more reliable result due to large pressure variation. The variation of pressure then will cause a change in the film thickness. A ball on disc is appropriated as the physical problem for this modeling simulation. Where it is presented as a point contact, such as a spherical surface contacted with plane [10]. Analyses are conducted for two dimension Reynold-equation. The material of the pin and disc are steel, which its elastic modulus (E) is $(210 \mathrm{GPa})$ and poisons' ratio $(\nu=0.3)$. The Oils used as lubricants in this analysis are (0W-30 and 10W-40). The temperature used are between $\left(-20\right.$ and $\left.120{ }^{\circ} \mathrm{C}\right)$ because this range of temperature is available in most machines. Dynamic viscosities and temperatures are shown in (Table 1) [11]. The other input parameters for this simulation are assumed constant. (a): EHL point contact

(b): Equivalent reduced geometry

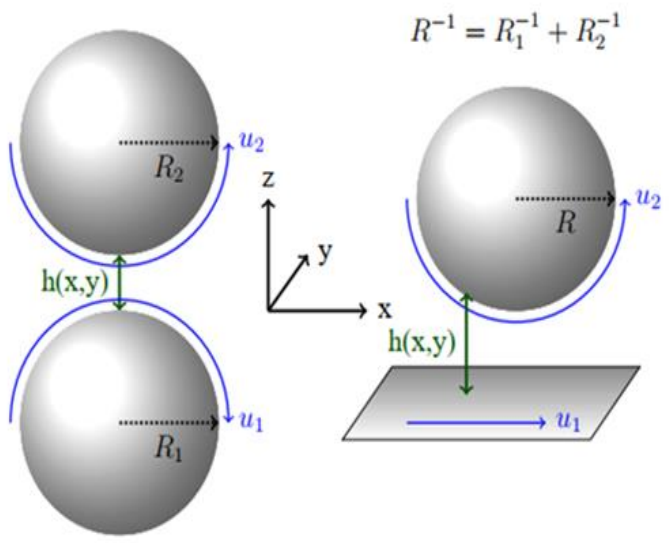

Figure (1): A representation of EHL point contact [3].

Table (1): Viscosity values with Temperatures

[11].

\begin{tabular}{|c|c|c|}
\hline $\begin{array}{c}\mathbf{T} \\
{\left[{ }^{\circ} \mathbf{C}\right]}\end{array}$ & $\begin{array}{c}\boldsymbol{\eta} \text { of 10W-40 } \\
{[\mathbf{m P a} . \mathbf{}]}\end{array}$ & $\begin{array}{c}\boldsymbol{\eta} \text { of } \mathbf{0 W}-30 \\
{[\mathbf{m P a} . \mathbf{}]}\end{array}$ \\
\hline-20 & 735.42 & 474.65 \\
\hline 0 & 385.53 & 249.94 \\
\hline 20 & 208.89 & 142.17 \\
\hline 40 & 79.330 & 55.926 \\
\hline 60 & 37.147 & 27.008 \\
\hline 80 & 19.690 & 15.064 \\
\hline 100 & 15.093 & 11.734 \\
\hline 120 & 11.877 & 9.3466 \\
\hline
\end{tabular}

\section{Governing Equations}

The governing equations of the steady state, point contact EHL using Newtonian lubricants can be described as follows: Supposing the fluid flow is laminar, and neglect the compressibility of fluid the Reynolds equation for point contact EHL problem that showed in figure (1), given as [12]:

$\frac{\partial}{\partial x}\left(\frac{\rho h^{3}}{\eta} \frac{\partial p}{\partial x}\right)+\frac{\partial}{\partial y}\left(\frac{\rho h^{3}}{\eta} \frac{\partial p}{\partial y}\right)=12 u \frac{\partial \rho h}{\partial x}$

Where: $\mathbf{u}=\frac{\mathbf{u} \mathbf{1}+\mathbf{u} \mathbf{2}}{\mathbf{2}}$ average speed. The nondimensional parameters used for converting the problem to dimensionless state are as follows [13]:

$X=\frac{x}{a}$ as a result $x=a X \rightarrow d x=a d X, Y=\frac{y}{a}$ as a result $\mathrm{y}=\mathrm{a} \mathrm{Y} \rightarrow \mathrm{dy}=\mathrm{a} \mathrm{dY}$

$P=\frac{p}{P_{h}}$, as a result $\mathrm{p}=\mathrm{Ph} \mathrm{P} \rightarrow \mathrm{dp}=\mathrm{Ph} \mathrm{dP}$

$\mathrm{H}=\frac{\mathrm{hR}_{\mathrm{x}}}{\mathrm{a}^{2}}, \quad \rho^{*}=\frac{\rho}{\rho_{\mathrm{o}}}, \eta^{*}=\frac{\eta}{\eta_{\mathrm{o}}}, \mathrm{W}=\frac{\mathrm{w}}{\mathrm{ER}_{\mathrm{x}}^{2}}$,

$\mathrm{G}=\alpha \mathrm{E} \quad, \quad \mathrm{U}=\frac{\eta_{\mathrm{o}} \mathrm{u}}{2 \mathrm{ER}_{\mathrm{x}}}$

Then Reynolds equation in non-dimensional form is became as follows [12]:

$$
\frac{\partial}{\partial \mathrm{X}}\left(\varepsilon \frac{\partial \mathrm{P}}{\partial \mathrm{X}}\right)+\mathrm{k} \frac{\partial}{\partial \mathrm{Y}}\left(\varepsilon \frac{\partial \mathrm{P}}{\partial \mathrm{Y}}\right)-\frac{\partial\left(\rho^{*} \mathrm{H}\right)}{\partial \mathrm{X}}=0
$$

Where: $\mathrm{K}$ is the ratio of (a to b), $(\mathrm{K}=1$ when $\Delta \mathrm{X}=$ $\Delta \mathrm{Y}$ ) the mesh generation is equally divided in two direction. In this study we will use $(\Delta \mathrm{X}=\Delta \mathrm{Y})$.

$$
\varepsilon=\frac{\rho^{*} H^{3}}{\eta^{*} \lambda} \text {, and } \lambda=\frac{12 \eta_{\mathrm{o}} \mathbf{u R}_{\mathrm{x}}^{2}}{\mathrm{a}^{3} \mathbf{P}_{\mathrm{h}}} \text {. }
$$

The boundary conditions are as follows:

$P(i, 1)=P(1, j)=0$ Pressures at the inlet 
$P=\frac{\partial P}{\partial X}=\frac{\partial P}{\partial Y}=0$ on cavitation boundary at the exit.

The film-thickness of EHL at any point on the contact surfaces is as follows [12]:

$$
\mathrm{H}=\mathrm{H}_{\mathrm{o}}+\frac{\mathrm{X}^{2}+\mathrm{Y}^{2}}{2}+\mathrm{H}_{\mathrm{def}}(\mathrm{X}, \mathrm{Y})
$$

Where the elastic deformation is as follows [12]:

$$
H_{\text {def }}(X, Y)=\frac{2}{\pi^{2}} \iint_{y_{a} x_{0}}^{y_{b} x_{e}} \frac{P\left(X^{\prime}, Y^{\prime}\right) d X^{\prime} d Y^{\prime}}{\sqrt{\left(X-X^{\prime}\right)^{2}+\left(Y-Y^{\prime}\right)^{2}}}
$$

The density and viscosity of oils are a function of pressure. Roeland-equation used to calculate the viscosity is as follows [14]:

$$
\eta^{*}(p)=e^{\left\{\left(\ln \eta_{\mathrm{o}}+9.67\right)\left[-1+\left(1+\frac{P p_{h}}{p_{o}}\right)^{z}\right]\right\}}
$$

Non-dimensional form of density equation that are given by Dowson and Higginson will be used, and it is as follow [15]:

$$
\rho^{*}(\mathrm{P})=1+\frac{0.59 \times 10^{-9} \mathrm{P} \mathrm{p}_{\mathrm{h}}}{1+1.7 \times 10^{-9} \mathrm{P} \mathrm{p}_{\mathrm{h}}}
$$

The load balance equation in non-dimensional form is as [12]:

$$
\iint_{y_{a} x_{o}}^{y_{b} x_{e}} P(X, Y) d X d Y=\frac{2}{3} \pi=0
$$

The friction force can be calculated by integrating the shear stress on the surface along the entire lubricating area. Friction force equation is as follows [12]:

$$
F=\left.\iint \tau\right|_{z=0, h} d x d y
$$

Where the shear stress is as follows [12]:

$$
\tau=\frac{1}{2} \frac{\partial P}{\partial X}(2 z-h)+(u h-u o) \frac{\eta}{h}
$$

Substituting the lower surface coordinate $(Z=0)$ and the upper surface coordinate $(\mathrm{Z}=\mathrm{h})$ in the above equation, and integrating gives the friction forces on the two surfaces. In this study, the friction on the lower surface are used. After obtaining the friction force, the friction coefficient could be calculated [12] $(\mu=F / W)$, as well as the viscous friction power losses.

\section{Numerical Technique}

With the central and forward discrete differential formulas, the discrete form of the non-dimensional Reynolds equation (2) can be calculated. By numerical integral, the dimensionless film-thickness equation (3) and load balance equation (7) also can be written in the discrete forms. These equations are given as follows: final iteration equation of Reynolds-equation for calculating new pressure is as follows [15]:

$$
P_{i j}=\frac{r-\Delta X \rho_{i j}^{*} D_{1} P_{i j}+\Delta X \rho_{i-1, j}^{*} D_{2} P_{i j}}{\varepsilon_{o}-\Delta X \rho_{i j}^{*} D_{1}+\Delta X \rho_{i-1, j}^{*} D_{2}}
$$

Film thickness equation [12]:

$$
\mathrm{H}_{\mathrm{ij}}=\mathrm{H}_{\mathrm{o}}+\frac{\mathrm{X}_{\mathrm{i}}^{2}+\mathrm{Y}_{\mathrm{i}}^{2}}{2}+\frac{1}{\pi^{2}} \sum_{\mathrm{k}=1}^{\mathrm{nn}} \sum_{\mathrm{l}=1}^{\mathrm{nn}} \mathrm{D}_{\mathrm{ij}}^{\mathrm{kl}} \mathrm{P}_{\mathrm{kl}}
$$

Load balance equation [12]

$$
\Delta \mathrm{X} \Delta \mathrm{Y} \sum_{\mathrm{i}=1}^{\mathrm{nn}} \sum_{\mathrm{j}=1}^{\mathrm{nn}} \mathrm{P}_{\mathrm{ij}}-\frac{2 \pi}{3}=0
$$

As the elastic-deformation and viscosity change with pressure, the following steps of the method used to solve the problem. First, assumed an initial condition. The initial pressure are (Hertzian pressure). Calculate the film-thickness, density, and viscosity. Substitute it in equation (9), to calculate a new pressure. The cavitation is handled by set the negative pressure to be zero. Repeat the steps until the difference between the pressures' distributions are less than the error that is given, which is about $10 \mathrm{E}-5$ or less. When the convergence is done, the final pressure distributions and film-thickness with elastic-deformation are calculated. Then calculate the friction force and coefficient of friction. The convergence equation that is used to end the iteration is as follows [12]:

$$
\frac{\sum \mathrm{P}_{\mathrm{i}}^{\mathrm{n}}-\mathrm{P}_{\mathrm{i}}^{\mathrm{o}}}{\sum \mathrm{P}_{\mathrm{i}}^{\mathrm{n}}}<\mathrm{e}=10^{-4}
$$

The hereafter iterative procedure was followed to solve the simultaneous system of compressible Reynolds' equation (2), elasticity-equation (4), and film-thickness equation (3). The flow chart shown in figure (2) illustrates the computational procedure implemented in the program. The input data to the program are shown in (Table 2).

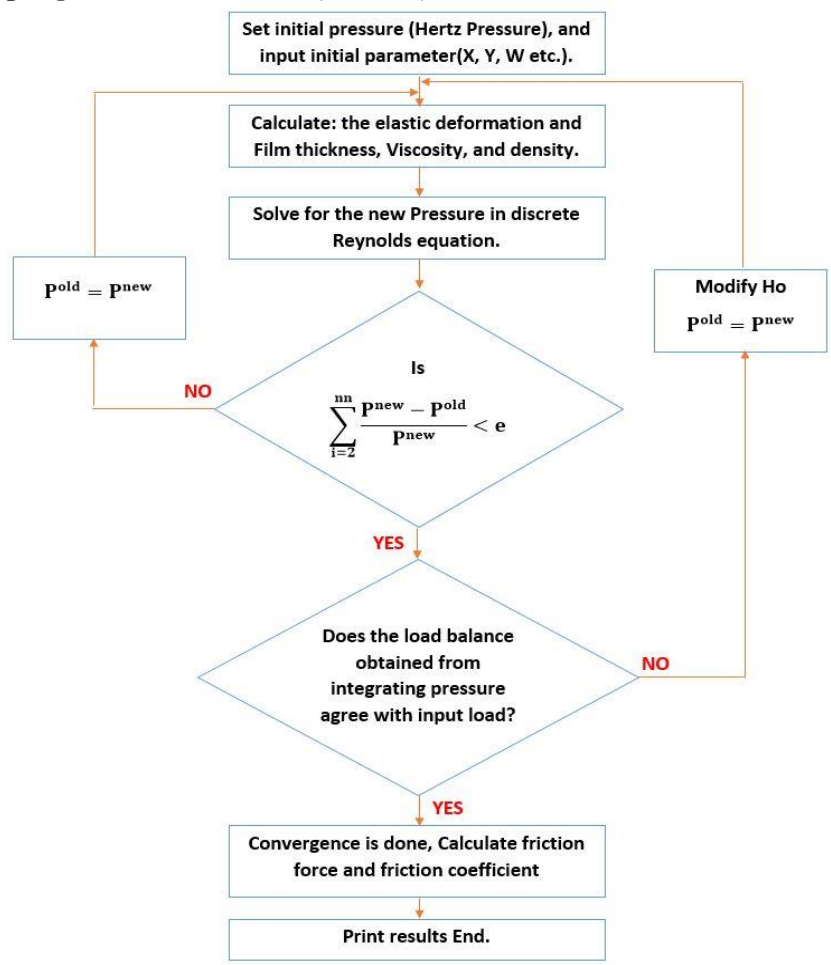

Figure (2): Flow chart of calculation procedure.

Table (2): Data input in program calculation

\begin{tabular}{|c|c|}
\hline Parameters & Values \\
\hline $\mathrm{nn}$ & $33 \times 33$ \\
\hline $\mathrm{W}$ & $100 \mathrm{~N}$ \\
\hline $\mathrm{Xo}$ & -2.0 \\
\hline $\mathrm{Xe}$ & 1.5 \\
\hline $\mathrm{Yo}$ & -2.0 \\
\hline $\mathrm{Ye}$ & 1.5 \\
\hline $\mathrm{u}$ & $1.5 \mathrm{~m} / \mathrm{s}$ \\
\hline $\mathrm{R}$ & $0.025 \mathrm{~m}$ \\
\hline $\mathrm{Z}$ & $0.68[16]$ \\
\hline $\mathrm{E}$ & $221 \mathrm{GPa}[16]$ \\
\hline
\end{tabular}




\section{Results and Discussion}

Results are presented in dimensionless form in figure (3 and 4) are obtained from the developed program. This results have a good agreement with that results presented by Ranger A.P, et al. [17]. This represents the characteristic feature for the isoviscous elasto-hydrodynamic regime [18, 19].

The initial minimum film thickness used was calculated from equation of Hamrock and Dowson [19] for point contact in non-dimensional form:

$$
\mathrm{H}_{\text {min }}=3.63 \mathrm{U}^{0.68} \mathrm{G}^{0.49} \mathrm{~W}^{-0.073}\left(\frac{\mathrm{R}_{\mathrm{x}}}{\mathrm{a}}\right)^{2}
$$

The range of initial non-dimensional minimum film-thickness and the three parameters of Hamrock and Dowson of point contact that calculated are shown in (table 3$)$.

Figures ( $5 \mathrm{a}$ and $5 \mathrm{~b})$ show the pressure profile of the centerline in $\mathrm{X}$ direction of contact region with temperature changes. Whenever temperature increases the oil viscosity decreases, the pressure profile is altered, Inlet pressure is reduced, and the pressure profile tends towards a Hertzian (dry contact) one. Figures ( $6 \mathrm{a}$ and $6 \mathrm{~b}$ ) show the filmthickness profile of the centerline in $\mathrm{X}$ direction of contact region with temperature variations. The film thickness decreases with the decrease of the viscosity as result of temperature increase.

Figure (7) show the variation of maximum pressure (Pmax) with the change of temperature. When the temperature increases the maximum pressure is not affected and remain approximately constant. Figure (8) show the variation of minimum film thickness (Ho), where it decreases gradually with the increase of temperature (decrease of viscosity). Where the minimum film thickness is directly proportional with the viscosity as in Hamrock equation. Figure (9) show the variation of friction force, it decreases gradually with the temperature increase. Figure (10) show the variation of friction coefficient where it decreases with the decrease of oil viscosity. Figure (11) show the load carrying capacity, where it remain equal to the given applied load.

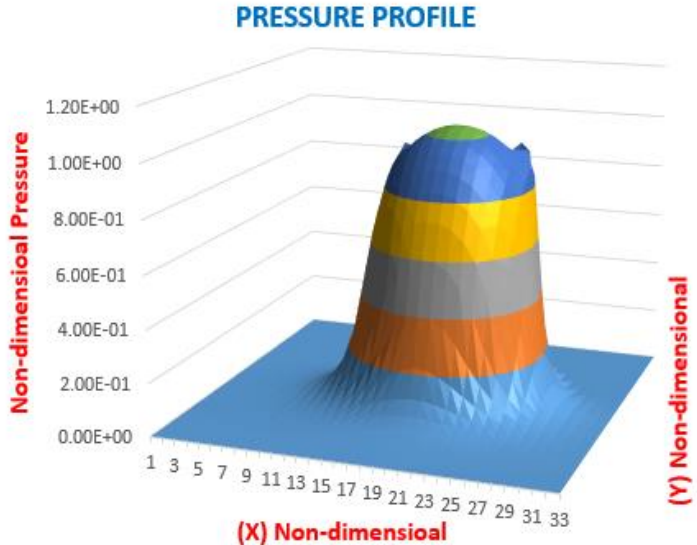

플 $0.00 \mathrm{E}+00-2.00 \mathrm{E}-01=2.00 \mathrm{E}-01-4.00 \mathrm{E}-01=4.00 \mathrm{E}-01-6.00 \mathrm{E}-01$ $=6.00 \mathrm{E}-01-8.00 \mathrm{E}-01=8.00 \mathrm{E}-01-1.00 \mathrm{E}+00=1.00 \mathrm{E}+00-1.20 \mathrm{E}+00$

Figure (3): Non-dimensional pressure profile.
FILM THICKNESS PROFILE

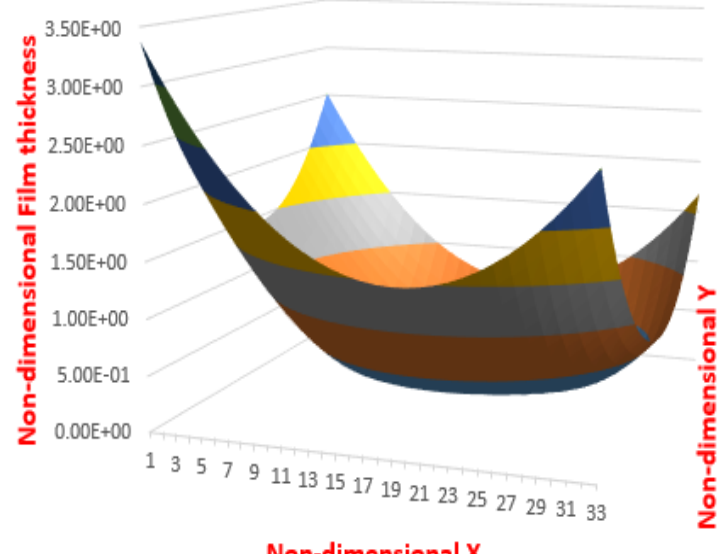

Figure (4): Non-dimensional film-thickness profile.

Table (3): The range of parameters for (-20 to 120 $\left.{ }^{\circ} \mathrm{C}\right)$

\begin{tabular}{|c|c|c|}
\hline Parameters & 0W-30 Oil & 10W-40 Oil \\
\hline \multirow{2}{*}{$\mathrm{H}_{\min }$} & $\begin{array}{c}5.0327 \mathrm{E}-01 \text { to } \\
7.5308 \mathrm{E}-02\end{array}$ & $\begin{array}{c}5.7581 \mathrm{E}-01 \text { to } \\
1.0035 \mathrm{E}-01\end{array}$ \\
\hline \multirow{2}{*}{$\mathrm{W}^{*}$} & $7.2398 \mathrm{E}-07$ & $7.2398 \mathrm{E}-07$ \\
\hline \multirow{2}{*}{$\mathrm{U}^{*}$} & $3.3361 \mathrm{E}-11$ to & $4.2398 \mathrm{E}-11$ to \\
& $2.7013 \mathrm{E}-12$ & $3.9366 \mathrm{E}-12$ \\
\hline \multirow{2}{*}{$\mathrm{G}$} & 5600.34 to & 5725.23 to \\
& 3890.50 & 4450.16 \\
\hline
\end{tabular}

\section{PRESSURE PROFILE}

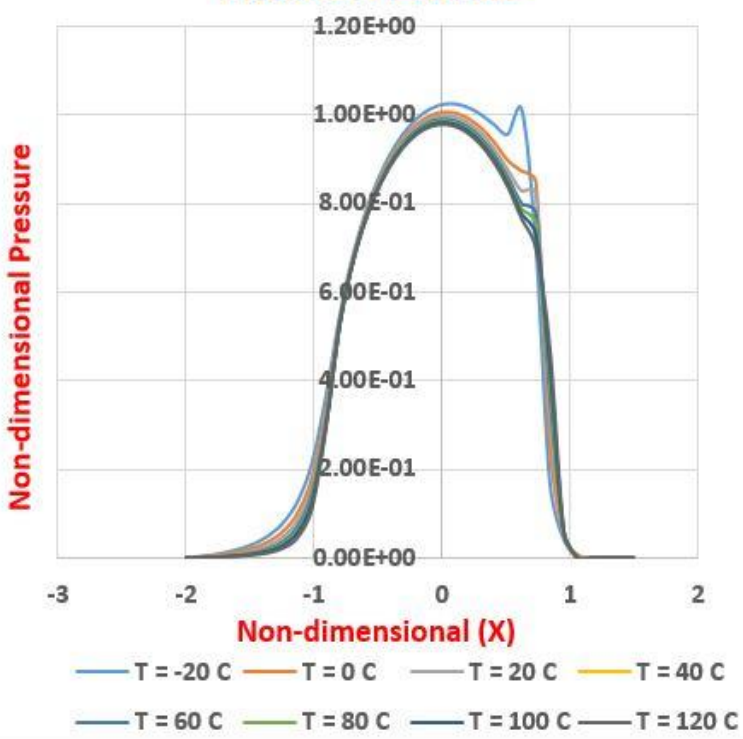

Figure (5a): The variation of Pressure profile with Temperature (0W-30 Oil). 


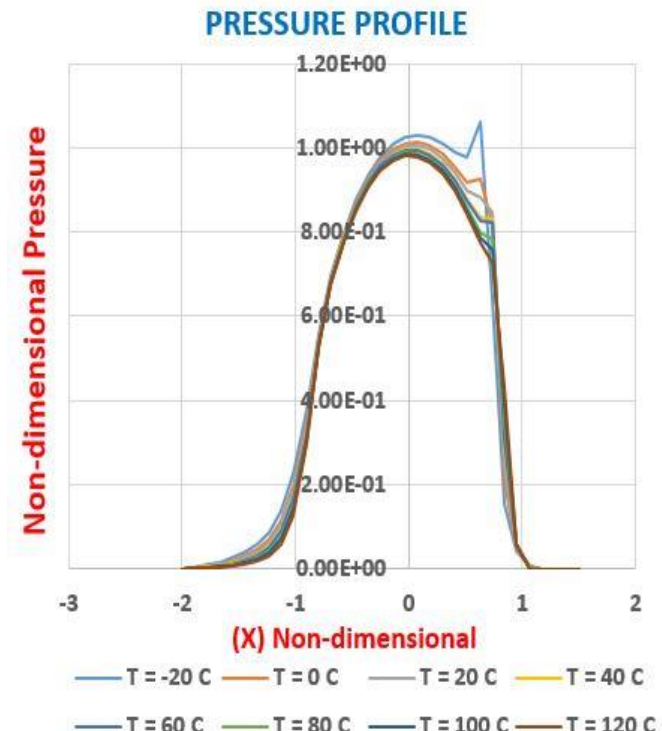

Figure (5b): The variation of Pressure profile with Temperature (10W-40 Oil).

FILM THICKNESS PROFILE

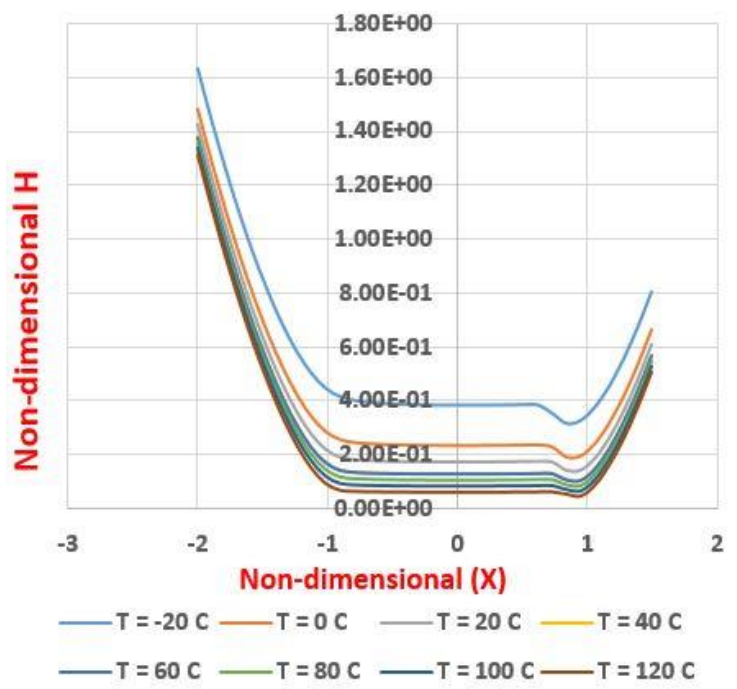

Figure (6a): The variation of film-thickness profile with Temperature (0W-30 Oil).

FILM THICKNESS PROFILE

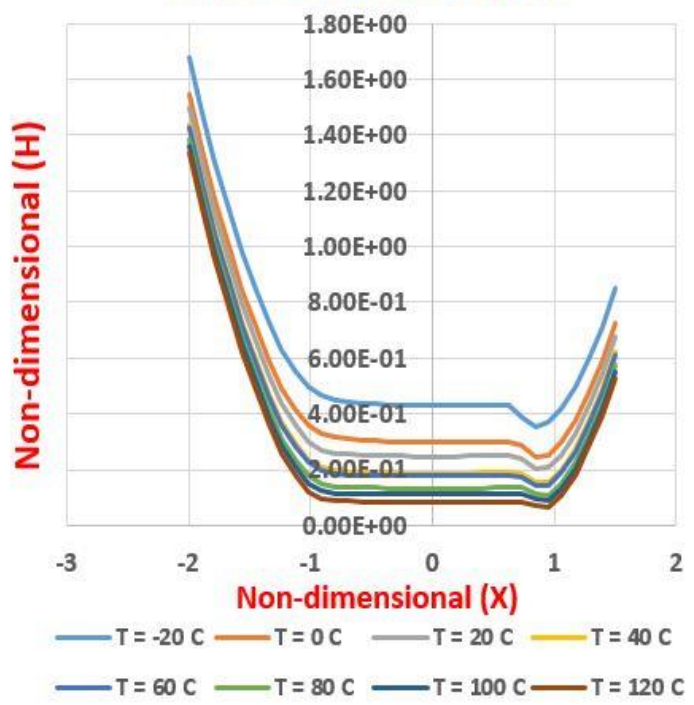

Figure (6b): The variation of film-thickness profile with Temperature (10W-40 Oil).
T vs Pmax

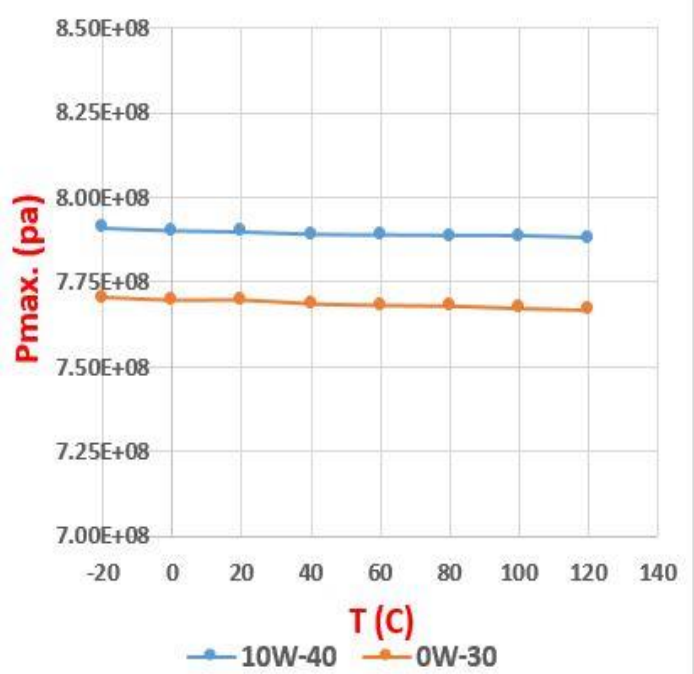

Figure (7): The variation of maximum pressure with Temperature.

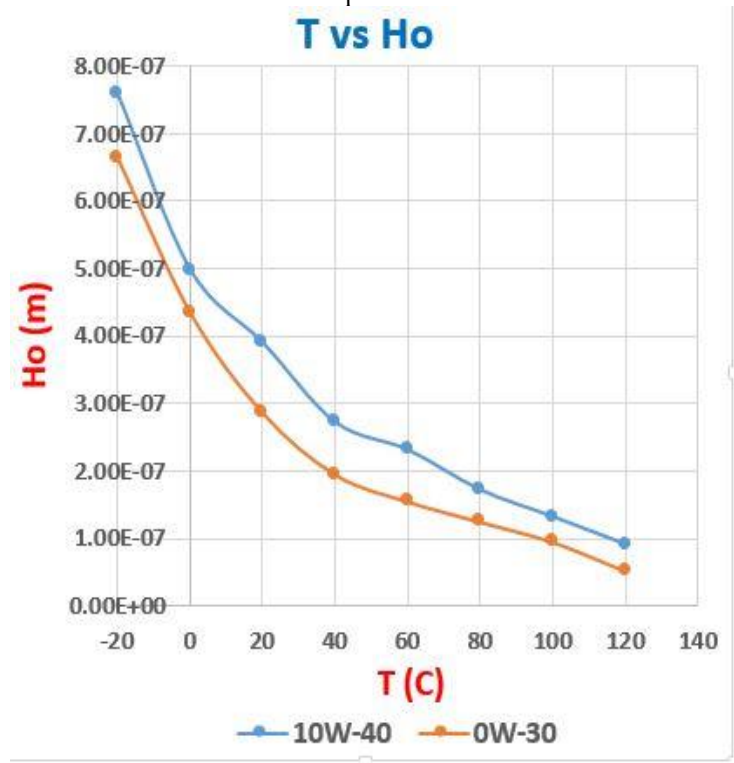

Figure (8): Variation of minimum film-thickness with Temperature.

\section{T vs F}

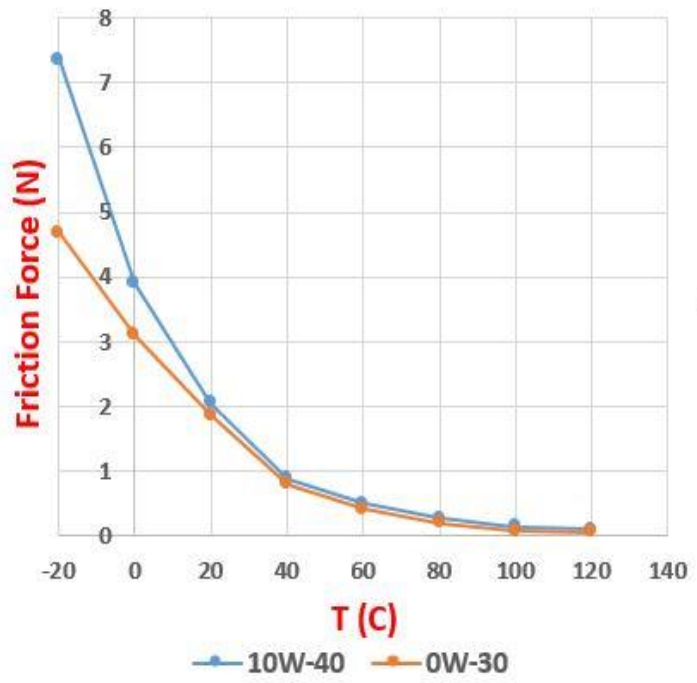

Figure (9): The variation of friction force with Temperature. 


\section{T vs $\mu$}

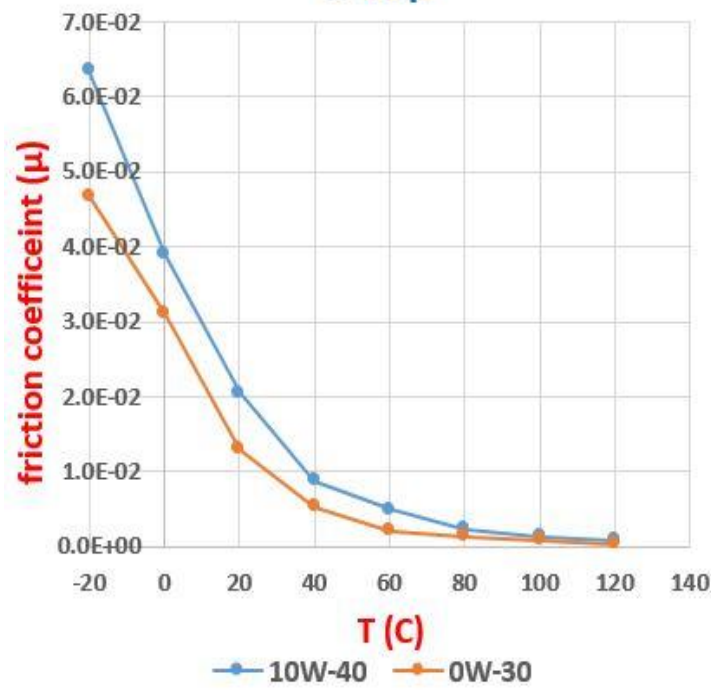

Figure (10): The variation of friction coefficient with Temperature.

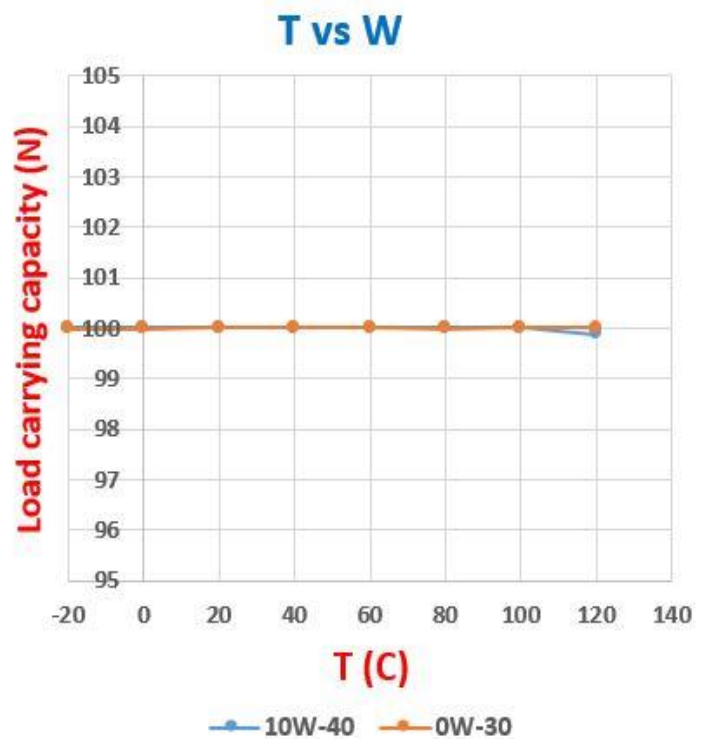

Figure (11): The variation of load with Temperature.

\section{Conclusion}

The Numerical results presented in this study confirm the results of several previous analysis available in literature. For the increasing of oil temperature in EHL contacts case, it can be concluded:

- The maximum pressure is not affected. Only the pressure profile is affected, the inlet pressure decreases, and pressure profile tends to Hertzian (dry contact) because of the decreases of viscosity and film thickness of lubricant in contact.

- The minimum film thickness decreases gradually approximately by $90.2 \%$, because of the decreases of viscosity. Where the minimum film thickness is directly proportional with the viscosity as in Hamrock equation.

- The friction coefficient decreases approximately by $96.4 \%$, because of the decreases of lubricant viscosity.
- The load carrying capacity remain constant and equal to applied load.

\section{References:}

[1]. Spikes H. Basics of EHL for practical application. Lubrication science. 27(1):45-67 Jan 2015.

[2]. W. Habchi. A Full-System Finite Element Approach to Elastohydrodynamic Lubrication Problem: Application to Ultra-Low-Viscosity Fluids. PhD thesis, University of Lyon, France, 2008.

[3]. S. Ahmed, Efficient Finite Element Simulation of Full System Elastohydrodynamic Lubrication Problems (Ph.D. thesis), University of Leeds, Leeds, UK, 2012.

[4]. J. de Vicente, J. R. Stokes, and H. A. Spikes, "The frictional properties of Newtonian fluids in rolling - Sliding soft-EHL contact," Tribol. Lett., vol. 20, no. 3-4, pp. 273-286, 2005.

[5]. P. Svoboda, D. Kostal, I. Krupka, and M. Hartl, "Experimental study of starved EHL contacts based on thickness of oil layer in the contact inlet," Tribol. Int., vol. 67, pp. 140-145, 2013.

[6]. W. Wang et al., "Simulations and Measurements of Sliding Friction Between Rough Surfaces in Point Contacts: From EHL to Boundary Lubrication," J. Tribol., vol. 129, no. 3, p. 495, 2007.

[7]. Björling, Marcus. "Friction in Elastohydrodynamic Lubrication." PhD diss., Luleå tekniska Universitet, 2014.

[8]. M. Björling, R. Larsson, P. Marklund, and E. Kassfeldt, "EHL friction mapping - The influence of lubricant, roughness, speed and slide to roll.," Proc. Inst. Mech. Eng. Part J J. Eng. Tribol., vol. 225, no. 7, pp. 671-681, 2011.

[9]. Hamrock BJ, Dowson D. Isothermal elastohydrodynamic lubrication of point contacts. Part I. Theoretical formulation. Transactions of the ASME, Journal of Lubrication Technology 98:223-229, 1976.

[10]. Y. Zhang, W. Wang, S. Zhang, and Z. Zhao, "Tribology International Experimental study of EHL fi $1 \mathrm{~m}$ thickness behaviour at high speed in ball- on-ring contacts," Tribiology Int., no. February, pp. 1-8, 2017.

[11]. Shigley, Joseph Edward. "Mechanical engineering design." P635 fig 12.14, 1972.

[12]. Wen S, Huang P. Principles of tribology. Second edition. John Wiley \& Sons; 2 June 2017.

[13]. Dowson D, Higginson G. R. Elastohydrodynamic Lubrication, SI edition. Pergamon Press: Oxford, 1977.

[14]. C.J.A. Roelands. Correlational Aspects of the Viscosity-Temperature-Pressure Relationship of Lubricating Oils. PhD thesis, Technische Hogeschool Delft, V. R. B., Groningen, The Netherlands, 1966.

[15]. C.H. Venner. Multilevel Solution of the EHL Line and Point Contact Problems. PhD thesis, 
University of Twente, Endschende, The Netherlands, 1991.

[16]. Goodyer, C. E., R. Fairlie, D. E. Hart, M. Berzins, and L. E. Scales. "Calculation of friction in steady-state and transient EHL simulations." In Tribology Series, vol. 43, pp. 579-590. Elsevier, 2003.

[17]. Ranger A.P., Ettles C.M.M. and Cameron A. 'The solution of the point contact elastohydrodynamic problem.' Proceedings of the Royal Society of London, Vol A346, pp. 227-244, 1975
[18]. S. Ahmed, C. E. Goodyer, and P. K. Jimack, "ScienceDirect An adaptive finite element procedure for fully-coupled point contact elastohydrodynamic lubrication problems," Comput. Methods Appl. Mech. Engrg., vol. 282, pp. 1-21, 2014.

[19]. B. J. Hamrock and D. Dowson, "Isothermal Elastohydrodynamic Lubrication of Point Contacts Part III - Fully Flooded Results," no. April, pp. 264-275, 1977.

\section{Notation}

\begin{tabular}{|c|c|c|c|}
\hline a & the half-width in the point contact & $\mathrm{w}$ & The applied load $(\mathrm{N})$. \\
\hline$D_{i j}^{k l}$ & $\begin{array}{c}\text { The two-dimensional elastic deformation } \\
\text { stiffness's. }\end{array}$ & W & The non-dimensional load. \\
\hline $\mathrm{E}$ & $\begin{array}{l}\text { The equivalent elastic modulus of the two } \\
\text { contact surface materials. }\end{array}$ & $\mathrm{W}^{*}$ & The load parameters. \\
\hline $\mathrm{F}$ & The Friction force $(\mathrm{N})$ & $\mathrm{X}$ & The non-dimensional coordinate of $\mathrm{x}$. \\
\hline G & A material parameter, $\mathrm{G}=\alpha \mathrm{E}$. & $\begin{array}{l}\mathrm{Xo} \\
\mathrm{Xe}\end{array}$ & $\begin{array}{c}\text { The non-dimensional coordinates of the inlet } \\
\text { and outlet. }\end{array}$ \\
\hline $\mathrm{h}$ & The oil film thickness (m). & $\mathrm{Y}$ & $\begin{array}{l}\text { The non-dimensional coordinate in the } y \\
\text { direction. }\end{array}$ \\
\hline hdef & The elastic deformation (m). & Z & The coordinate in the film thickness direction. \\
\hline ho & The minimum oil film thickness (m). & $\mathrm{z}$ & The coefficient of viscosity pressure formula. \\
\hline $\mathrm{H}$ & The non-dimensional film thickness. & $\alpha$ & $\begin{array}{c}\text { the pressure coefficient of oil viscosity- } \\
\text { pressure formula }\end{array}$ \\
\hline Hdef & The non-dimensional elastic deformation. & $\Delta \mathrm{X}$ & $\begin{array}{l}\text { The equally divided non-dimensional } \\
\text { increment between the nodes of the mesh. }\end{array}$ \\
\hline Ho & The non-dimensional central film thickness. & $\varepsilon$ & The Reynolds coefficient. \\
\hline nn & The number of nodes. & $\lambda$ & the parameter of the coefficients $\varepsilon$. \\
\hline $\mathrm{p}$ & The pressure $(\mathrm{Pa})$. & $\eta$ & The oil viscosity (Pa.s). \\
\hline $\mathrm{PH}$ & Hertz contact pressure $(\mathrm{Pa})$ & $\eta \mathrm{n}$ & The oil viscosity at PO. \\
\hline $\mathrm{P}$ & The non-dimensional pressure. & $\eta *$ & The non-dimensional viscosity of the lubricant. \\
\hline $\mathrm{R}$ & The equivalent radius of curvature (m). & $\mu$ & The friction coefficient. \\
\hline $\mathrm{T}$ & The temperature (OC). & $\varrho$ & The lubricant density $(\mathrm{Kg} / \mathrm{m} 3)$. \\
\hline $\mathrm{u}$ & $\begin{array}{l}\text { The average velocity of the upper and lower } \\
\text { surfaces contacted }(\mathrm{m} / \mathrm{s}) \text {. }\end{array}$ & $Q^{*}$ & The non-dimensional density of lubricant. \\
\hline $\mathrm{U}^{*}$ & The velocity parameters. & SSR & Slide to roll ratio \\
\hline
\end{tabular}

